\title{
First line in psychiatric emergency: pre- hospital emergency protocol for mental disorders in Iran
}

\author{
Fatemeh Shirzad ${ }^{1}$, Fatemeh Hadi ${ }^{2}$, Seyede Salehe Mortazavi ${ }^{1,{ }^{*}}$, Maryam Biglari ${ }^{4}$, Hassan Noori Sari ${ }^{5}$, \\ Zeinab Mohammadi ${ }^{6}$, Mehrdad Kazemzade Atoofi ${ }^{1}$ and Seyed Vahid Shariat ${ }^{7}$
}

\begin{abstract}
Introduction: This article is a report of designing a rapid and effective guide for paramedics who take care of patients in a pre-hospital setting to answer developing demands.

Methods: The relevant literature was reviewed, and the topics were extracted. Then, the extracted items were discussed in an expert panel. Finally, items were discussed in a meeting including emergency technicians and emergency technical assistants to identify implementation problems.

Results: Important topics for managing psychiatric patients were categorized at three levels: 1) Patient safety and security issues, 2) Patient status assessment and diagnosis, and 3) Patient management (medical, behavioral management, and referral to a treatment center).

Discussion: This protocol can be a solution to improve emergency technician training. Such summarized protocols can be used for rapid review immediately before exposing a patient with an acute psychiatric condition. Due to specific cultural and different access to medicines in Iran, some issues are different.
\end{abstract}

Keywords: Mental disorder, Protocol, Emergency, Pre-hospital

\section{Background}

Mental health problems are quite prevalent and pose a heavy burden on a society. According to the Burden of Disease study performed in Iran in 2003, mental and behavioral disorders were ranked as the second in intentional and unintentional injuries [1]. Moreover, the latest national survey on mental disorders has shown that a one-year prevalence of psychiatric disorders in Iran is $23.6 \%$ [2]. A small but significant proportion of these patients would need intensive care, sometime during the course of their disease. In such a psychiatric

\footnotetext{
* Correspondence: Mortazavi.ss@iums.ac.ir; salehe.mortazavi@gmail.com 'Spiritual Health Research Center, Iran University of Medical Sciences, Tehran, Iran

${ }^{3}$ School of Behavioral Sciences and Mental Health (Tehran Institute of Psychiatry), Iran University of Medical Sciences, Tehran, Iran Full list of author information is available at the end of the article
}

emergency, paramedics are in the front line of emergency medical service (EMS) for assessing, managing and transferring patients to the emergency wards of hospitals. Therefore, the role of paramedics is critical in rapid and accurate decision making.

Despite the vital role of paramedics in pre-hospital management of psychiatric problems, little evidence exists on the issue [3]. Paramedics have three major needs for a good performance: knowledge, skill for an appropriate clinical decision making, and organizational factors [3]. Educational courses have been shown to improve their knowledge, attitude, skill, and self-efficacy in performing the job and also will help them in better decision making on the scene [4-6].

Emergency paramedic may face many difficulties in making decisions for emergency patients with mental

(C) The Author(s). 2020 Open Access This article is licensed under a Creative Commons Attribution 4.0 International License, which permits use, sharing, adaptation, distribution and reproduction in any medium or format, as long as you give appropriate credit to the original author(s) and the source, provide a link to the Creative Commons licence, and indicate if changes were made. The images or other third party material in this article are included in the article's Creative Commons licence, unless indicated otherwise in a credit line to the material. If material is not included in the article's Creative Commons licence and your intended use is not permitted by statutory regulation or exceeds the permitted use, you will need to obtain permission directly from the copyright holder. To view a copy of this licence, visit http://creativecommons.org/licenses/by/4.0/. The Creative Commons Public Domain Dedication waiver (http://creativecommons.org/publicdomain/zero/1.0/) applies to the data made available in this article, unless otherwise stated in a credit line to the data. 
illness [7]. They should prioritize safety in the first place and simultaneously assess the patients for possible physiological, psychiatric, pathological, socio-cultural, and legal aspects to reach an accurate diagnosis and also manage plans $[8,9]$. Additionally, they are frequently exposed to the aggressive behavior of violent patients [10] and inappropriate management of aggressive behavior can have severe consequences. In the case of highly aggressive patients, chemical and physical restraint should be performed very cautiously [11] under clinical guidelines [10].

Emergency staffs are at the risk of cumulative stress because of the high amount of stress they experience; and if it is not adequately addressed, emotional trauma and its related dysfunction would appear [12]. Paramedic's workloads for mental illness are growing and their ability for decision making in the complex situation of psychiatric emergency should be amended [4]. Furthermore, their ability to triage patients with psychiatric problems is limited and, in some cases, paramedics admitted the necessity of assessment tools and training courses for maintaining the capability of emergency services $[4,6,12,13]$. Therefore, they will benefit from educational courses and rapid clinical protocols that would help them with their clinical decision making [6]. This article is a report of the process of designing a rapid and effective guide for paramedics who take care of patients to answer increasing demands in a pre-hospital setting.

\section{Methods}

This project was conducted at the request of the Technical Assistance and Operations Department of the Iranian Emergency Organization. Firstly, the relevant literature was reviewed. To prevent bias and to enrich resources, in addition to the chapters on managing patients with acute psychiatric symptoms in psychiatric textbooks, more specialized resources in the field of emergency psychiatric patient's management were also reviewed. We also searched for recent related articles in PubMed, Scopus, and Web of Knowledge databases.

We combined keywords related to emergency situation including "psychiatric emergency", "behavioral emergency", "agitated behavior", "agitation", "violence", and "aggression" with terms of "management", "protocol" and "prehospital care". Mesh terms, expert opinion, and some keywords from the existing literature review were used to select these keywords. Then, we screened the retrieved articles and removed the unrelated articles.

17 documents out of 56 primitive cases were selected which their information has been presented in Table 1. The criterion for omitting the articles was decided by research team based on the critical appraisal using peer review checklist for protocol recommended by Cochrane Community [14].
Finally, we extracted the topics in the remaining related articles. The extracted topics were then classified based on seven criteria as follows: 1) Order of execution (at what stage they should execute), 2) first encounter with the patient and maintaining safety, 3) Evaluation and taking a medical history, 4) The primary differential diagnoses, 5) Behavioral and drug therapy and management, 6) Decreasing life-threatening risks in patients, and 7) Repeatable rate in different sources. Based on these categories, an early draft of the protocol was written. The draft was sent to 10 psychiatrists who expert in emergency psychiatry and their initial feedbacks were collected. Some changes were made in the protocol, according to the experts' comments. In the next step, an expert panel was held.

The panel included experts from psychiatry, forensic medicine, clinical psychology, emergency medicine, Emergency Technical Assistant (deputy) and a general physician. In the panel, each expert commented on each of the items and stages according to the following questions:

1. To what extent is it necessary?

2. To what extent is it clear to the emergency technician?

3. To what extent is it generalizable to similar symptoms in other emergencies (e.g., acute restlessness in non-psychiatric patients)?

4. To what extent can it be done according to the equipment and situation of our society?

5. To what extent has patient safety been considered at this stage?

6. To what extent has the safety of emergency technicians been considered?

7. To what extent is the safety of the patient's relatives and those present at the scene taken into account?

8. Considering the current law, how legal is any of the actions of emergency technicians?

Each item was scored using a Likert scale from very low [1] to very high [9]. After adding the scores based on the expert's decisions, Items with a mean score 6 and higher, remained unchanged in the protocol and those with a mean score of 3 and lower were eliminated from the protocol. Other Items were discussed once more and were finally agreed upon with some minor changes.

The above case was presented in a meeting of 60 emergency technicians (with more than 15 years of working experience) from different cities of Iran. Applicability, clearness and comprehensibility of items were discussed. The ambiguities of the protocol were addressed, and the implementation issues of the protocol were identified. The protocol was finalized in 2 pages that were applicable in an ambulance for reviewing important points when confronting with psychiatric patients. 
Table 1 The main data of the Included studies

Title Author/s Time Desig

Target

population

Emergency psychiatry: physical and chemical restraint in the psychiatric emergency service

Currier GW., 2000 Review et al

Pharmacological management of acute agitation

A growing evidence base for management guidelines: Revisiting Guidelines for the Management of Acutely Disturbed Psychiatric Patients

R., et al
The expert consensus guideline series. Treatment of behavioral

emergencies

\section{Battaglia J. 2005 Clinical experience}

Macpherson 2005 Review

Allen M., 2005 Expert panel et al

Pychiatric patient with acute symptoms intervention in care systems.

Atypical antipsychotic medications in the management of disruptive behaviors in children: safety guidelines and recommendations

Haloperidol for et al

Cunha S., 2009 RCT

McKinney C., 2011 Review

et al

Powney MJ., 2012 Systematic
Patient with agitation

assessment of the effect of antipsychotics in agitation control of psychiatric emergency patients

Children and providing guidelines adolescents for the use of with Disruptive antipsychotics in Behavior children

Psychiatric defining important factors for formulating recommendations and guidelines for agitation control in emergency patients
Identifying and

Main points/ result

Sample size

Physical and chemical restraints are important for optimal

management of agitated and aggressive patient restrain for Rapid agitated patients in emergencies

recommendations drugs to psychiatric management patients with aggression

r

medications for rapid tranquilization have been obtained.

Appropriate recommendations for aggressive management patients included adjustment of environment and verbal relaxation

Defining the following 50 experts elements: the

threshold for

emergency

interventions, the scope of assessment for varying levels of urgency and cooperation, guiding principles in selecting interventions, and appropriate physical and medication strategies at different levels of diagnostic confidence and for a variety of etiologies and complicating conditions.

Olanzapine and haloperidol are the best and safe drugs to control patients' agitation

Studies do not prove the safety of prescribing antipsychotics in children. Further and more detailed studies are needed.

Assessment effect of Haloperidol can be 
Table 1 The main data of the Included studies (Continued)

\begin{tabular}{|c|c|c|c|c|c|c|c|}
\hline Title & Author/s & Time & Design & $\begin{array}{l}\text { Target } \\
\text { population }\end{array}$ & objective & Main points/ result & Sample size \\
\hline $\begin{array}{l}\text { psychosis-induced } \\
\text { aggression or agitation } \\
\text { (rapid tranquillization). } \\
\text { Cochrane database of } \\
\text { systematic reviews }\end{array}$ & et al & & review & $\begin{array}{l}\text { patient } \\
\text { with agitation }\end{array}$ & $\begin{array}{l}\text { haloperidol (oral, } \\
\text { IM and IV) in } \\
\text { agitated patient }\end{array}$ & $\begin{array}{l}\text { the first choice in } \\
\text { controlling the restless } \\
\text { of psychiatric patients } \\
\text { and can be quite } \\
\text { redemptive in their } \\
\text { treatment }\end{array}$ & \\
\hline $\begin{array}{l}\text { The } \\
\text { psychopharmacology } \\
\text { of agitation: consensus } \\
\text { statement of the } \\
\text { American Association }\end{array}$ & $\begin{array}{l}\text { Wilson MP., } \\
\text { et al }\end{array}$ & 2012 & Review & $\begin{array}{l}\text { Patient with } \\
\text { agitation }\end{array}$ & $\begin{array}{l}\text { providing a specific } \\
\text { guideline for the } \\
\text { management of } \\
\text { agitation in different } \\
\text { situations }\end{array}$ & $\begin{array}{l}\text { The main treatment for } \\
\text { agitation should be } \\
\text { based on the most } \\
\text { likely cause }\end{array}$ & - \\
\hline
\end{tabular}

Psychiatry Project BETA

Psychopharmacology

Workgroup

Issues in the

management of acute

agitation: how much

current guidelines

consider safety?

Frontiers in psychiatry

Intravenous droperidol

or olanzapine as an

adjunct to midazolam

for the acutely

agitated patient: a

multicenter,

randomized, double-

blind, placebo-

controlled clinical trial

Risk for physical restraint or seclusion in the psychiatric emergency service (PES). General hospital psychiatry

Assessment and management of agitation in psychiatry: expert consensus. The world journal of biological psychiatry.

\author{
Haloperidol plus \\ promethazine for \\ psychosis-induced \\ aggression. Cochrane \\ Database of Systematic \\ Reviews.
}

Biological treatment of acute agitation or aggression with schizophrenia or bipolar disorder in the inpatient setting. Annals of clinical psychiatry

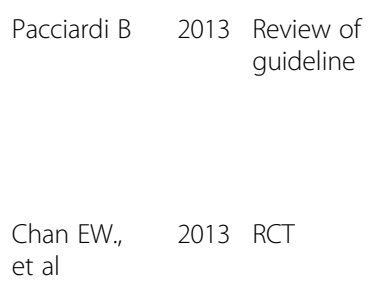

Simpson SA., 2014 Retrospectively et al reviewed medical records, nursing logs, and quality assurance data for all adult patient encounters in a PES Over a 12month period

Garriga M., 2016 Systematic review et al and Delphi and expert panel

Patient with agitation

Adult patient describe risk factors encountered in associated with a PES

Patient with
acute agitation

assessment of vailable and safe drugs for rapid tranquilization in agitative Patient in Emergency

Patient with to determine the efficacy and safety of intravenous droperidol or olanzapine as an adjunct to intravenous midazolam for rapid patient sedation. patients experiencing physical restraint or seclusion in the psychiatric emergency service (PES)

provide

comprehensive recommendations for agitation evaluation and management

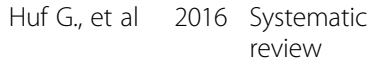
review

Correll CU., 2017 Review et al promethazine and
Patient with agitation

Psychotic patient with aggression

assessment The safety and effect of the combination of haloperidol vs haloperidol alone in an agitated patient

summarize the available biological treatment options for patients with schizophrenia or bipolar disorder presenting with acute agitation or aggression in the inpatient setting
The use of secondgeneration of anti psychotic is preferred

11 guidlines

Intravenous droperidol 336 patient or olanzapine as an adjunct to midazolam is effective and decreases the time to adequate sedation compared with midazolam alone.

Physical restraint when 5333 needed can be very helpful in calming agitated and violent patients

physical restrain without over sedation is useful for agitation management. Underline medical illness should be considered.

This combination is effective and safe but haloperidol alone is better

The use of secondgeneration of anti psychotic is preferred. The use of drugs should be based on patient tolerated
124 papers 
Table 1 The main data of the Included studies (Continued)

\begin{tabular}{|c|c|c|c|c|c|c|c|}
\hline Title & Author/s & Time & Design & $\begin{array}{l}\text { Target } \\
\text { population }\end{array}$ & objective & Main points/ result & Sample size \\
\hline $\begin{array}{l}\text { Managing acutely } \\
\text { aggressive or agitated } \\
\text { people in a psychiatric } \\
\text { setting: a survey in } \\
\text { Lebanon. }\end{array}$ & Dib JE., et al & 2018 & $\begin{array}{l}\text { A survey of } \\
\text { clinicians' } \\
\text { opinions and } \\
\text { practice was } \\
\text { conducted } \\
\text { between July and } \\
\text { August } 2017 \text { at the } \\
\text { largest psychiatric } \\
\text { hospital in Lebanon }\end{array}$ & $\begin{array}{l}\text { Psychiatric } \\
\text { Patient } \\
\text { with acute } \\
\text { symptoms }\end{array}$ & $\begin{array}{l}\text { Surveying treatments } \\
\text { in a psychiatric } \\
\text { setting in Lebanon }\end{array}$ & $\begin{array}{l}\text { There was a } \\
\text { consistent } \\
\text { view that there } \\
\text { should first be } \\
\text { verbal control, then } \\
\text { use of medications, } \\
\text { and finally physical } \\
\text { restrain of the patient } \\
\text { It was found evidence } \\
\text { of high family } \\
\text { involvement in } \\
\text { psychiatric emergency }\end{array}$ & $\begin{array}{l}\text { seven } \\
\text { experienced } \\
\text { psychiatrists }\end{array}$ \\
\hline $\begin{array}{l}\text { Managing agitation } \\
\text { associated with } \\
\text { schizophrenia and } \\
\text { bipolar disorder in the } \\
\text { emergency setting. }\end{array}$ & $\begin{array}{l}\text { Zeller SL., } \\
\text { et al }\end{array}$ & 2015 & $\begin{array}{l}\text { Review of (BETA) } \\
\text { guidelines with the } \\
\text { addition of data on } \\
\text { new pharmacologic } \\
\text { interventions }\end{array}$ & $\begin{array}{l}\text { Patient with } \\
\text { agitation }\end{array}$ & $\begin{array}{l}\text { Raise awareness } \\
\text { of best practices } \\
\text { for the management } \\
\text { of agitation in the ED } \\
\text { and to consider the } \\
\text { role of new } \\
\text { pharmacologic } \\
\text { interventions in } \\
\text { this setting. }\end{array}$ & $\begin{array}{l}\text { (BETA) guidelines } \\
\text { address the complete } \\
\text { management of } \\
\text { agitation } \\
\text { Newer modes of } \\
\text { delivery that could be } \\
\text { useful in rapidly } \\
\text { managing agitation } \\
\text { include inhaled, } \\
\text { buccal/sublingual and } \\
\text { intranasal formulations } \\
\text { Non-invasive } \\
\text { formulations have the } \\
\text { potential to improve } \\
\text { overall patient } \\
\text { experience }\end{array}$ & - \\
\hline $\begin{array}{l}\text { Pharmacologic } \\
\text { Management of } \\
\text { Agitation and } \\
\text { Aggression in a } \\
\text { Pediatric Emergency } \\
\text { Department-A } \\
\text { Retrospective Cohort } \\
\text { Study. }\end{array}$ & $\begin{array}{l}\text { Kendrick JG., } \\
\text { et al }\end{array}$ & 2018 & $\begin{array}{l}\text { Retrospective } \\
\text { observational } \\
\text { study }\end{array}$ & $\begin{array}{l}\text { Patients less } \\
\text { than } 20 \text { years } \\
\text { of age with } \\
\text { agitation and } \\
\text { aggretion }\end{array}$ & $\begin{array}{l}\text { To describe } \\
\text { medication utilization } \\
\text { in the management of } \\
\text { agitation and } \\
\text { aggression in a } \\
\text { pediatric ED and to } \\
\text { assess the safety of } \\
\text { their use. }\end{array}$ & $\begin{array}{l}\text { Benzodiazepine and } \\
\text { antipsychotic drug } \\
\text { therapy for acute } \\
\text { agitation and } \\
\text { aggression in children } \\
\text { appears to be safe and } \\
\text { well tolerated }\end{array}$ & 120 patient \\
\hline
\end{tabular}

\section{Results}

Based on the findings from the literature review and discussed issues in the expert panel, important topics for managing psychiatric patients were categorized in three levels: 1) Patient safety and security issues, 2) Patient status assessment and diagnosis and 3) Patient management (medical, behavioral management, and referral to a treatment center).

\section{Primary actions}

The first step is to ensure the safety of the patient, technicians, and people on the scene [15]. This stage includes: a) pre-scene assessments of site security, escape routes, and safe locations in the event of violence from the patient, b) assessment of patient's access to weapons and equipment that could threaten his/her own life, technicians or attendees [16], C) Assessment for risk and need for back up and the presence of police, which includes anticipating their entrance method and avoidance of entering the place alone, D) using family capacities to provide security [16] and E) Assessment of risk factors for violence and predicting it
Symptoms of imminent aggression include: 1) Motor restlessness and agitation, 2) The loud and threatening tone of voice, 3) Threatening behavior and gestures, 4) Verbal Threats, 5) Staring and angry face mode, 6) Sudden behaviors (He throws the object in his hand suddenly), 7) Bizarre behavior due to delusion and hallucination.

\section{Patient assessment}

Patient evaluation includes the following: A) Urgent physical needs by evaluating vital signs (Airway, presence of respiratory distress, and pulse), B) Obtaining a targeted mental health history of the patient from his or her family including: Demographic characteristics (sex, age, occupation), history of psychiatric illness, history of physical and primarily neurological diseases, history of drug abuse, history of violence or suicide [15], C) Differential diagnoses (psychological causes versus physical causes of symptoms) and physical risk factors (sudden onset of symptoms without previous history, age younger than 12 years and older than 60 years, known neurological diseases such as seizures or dementia, existence 
Table 2 Variety of physical origin of psychiatric emergency

\begin{tabular}{ll}
\hline Intoxication/withdrawal & Medical status \\
\hline - Alcohol intoxication/ withdrawal/delirium tremens & • Head trauma \\
- Substance intoxication/ withdrawal: & - Post-ictal condition \\
- Opioids & - Delirium \\
- Amphetamines & - Hypoglycemia \\
- cannabis & - Electrolyte disturbance (Hyponatremia, hypernatremia, hypokalemia, hyperkalemia ...) \\
- others & - Hypoxia \\
- Medical intoxication/ withdrawal: & - Encephalitis, Meningitis \\
- Benzodiazepines & - Encephalopathy (due to medical condition) \\
- Anticonvulsants & - Environmental toxicity \\
- others & - Thyroid dysfunction \\
\hline
\end{tabular}

of neurological symptoms such as ataxia, nystagmus and complex drug regimen (Table 2) [17] D) Considering cultural and spiritual aspects of patients which can effect on symptoms and how to help them.

\section{Patient management}

Patient management includes: a) behavioral management, b) pharmacological management, c) patient family management.

a) Patients' behavioral management includes following recommendations on how to behave and speak to the patient:

- Speak to the patient in a calm, measured and confident tone

- Reduce external stimuli, such as the noise and the provocative behavior of others [18]

- Reduce internal triggers like hunger and thirst, and offer water and food to the patient whenever possible.

- have empathic and non-judgmental attitudes and behaviors

- accept the patient's hallucinations and delusions appropriately

- Don't make a false promise to the patient

- Use short, simple sentences and repeat the sentences if necessary

- Listen to the patient

- Use patients' words as much as possible

- Reassure the patient that you understand the problem

- Encourage the patient to provide information to those who can help

- Attempt to meet the patient's spiritual needs (include general spiritual principles in the patient-therapist relationship, showing compassion and unconditional acceptance to the patient)

- Encourage the patient to provide information to those who can assist him/her.
In case of aggression, in addition to the mentioned points, Keep the patient at least $2 \mathrm{~m}$ away, tell the patient that aggression is unacceptable, offer medication and in order to prevent harm themselves or others, use physical restraint if $\mathrm{s} /$ he continues [19].

b) Pharmacological management: There are several important principles to consider in drug administration. The aim of emergency medical treatment should be to calm down the agitated patient as quickly as possible without reducing the patient's level of consciousness. Like all emergencies, oral drugs are preferred to injectable ones. The drug should be selected based on the onset of action and availability. Short-acting drugs are preferred over long-acting drugs. Medicines with fewer side effects are also preferred. Thus, in the first step, oral medications such as benzodiazepines or lorazepam with or without typical antipsychotics such as risperidone may be used.

In the second line, other antipsychotics such as haloperidol may be administered. If the patient's condition does not improve or he/she does not cooperate in the treatment, intramuscular antipsychotics such as Amp haloperidol $5 \mathrm{mg}$ along can be used. If necessary, these medications can be repeated with cardiac and blood pressure monitoring. Other medicines such as promethazine or injectable benzodiazepines may also be used to increase the effectiveness of the administered drugs [19-21] (Table 3).

Restraints may use with the pharmacological methods. This treatment option is used as the last choice in patients who are uncooperative and physically dangerous and may harm themselves or others, and when nonpharmacological and primary pharmacological methods are ineffective. In these cases, special care should be taken to protect the patient from life-threatening situations (Table 4).

In addition to the above-mentioned points, consider the Contraindications of restraining which include the followings [22, 23]: 
Table 3 Medical management

\begin{tabular}{ll}
\hline First line & Second line \\
\hline 1. Tab Risperidone $2 \mathrm{mg}$ & Tab Haloperidol $5 \mathrm{mg} \pm$ Tab Lorazepam \\
2. \pm Tab lorazepam $2 \mathrm{mg}$ & \\
3. Tab olanzapine $5-10 \mathrm{mg}$ & Amp Promethazine $50 \mathrm{mg}$ IM \\
Amp Haloperidol $5 \mathrm{mg} \pm$ amp lorazepam & \\
\hline
\end{tabular}

- Cases in which patients used Phencyclidine (PCP) based on the family history

- Patients with recent surgery in the eye or central nervous system (Because of an increase in intracerebral or intraocular pressure)

- patients with a low level of consciousness or with delirium

c) Intervention in the patient family including having empathy and understanding of the critical situations and psycho-education about the conditions and places that they can attend [24].

Management of suicide emergencies requires special consideration. The expert panel suggests that suicide emergencies need a separate protocol. Moreover, while drug and alcohol poisoning and deprivation have similar symptoms with psychological emergencies, they have a completely different treatment, and they need another protocol.

\section{Discussion}

A psychiatric emergency refers to any disturbances in a patient's thinking, emotions, or behavior that requires immediate intervention. This disruption usually puts patients in critical conditions, which can put them, their family, and people around them in danger. These emergencies include hurting others or themselves, aggression, restlessness, acute behavioral symptoms caused by drug poisoning, depression, and severe anxiety [15].

Table 4 Important recommendation points in physical restraint

- Explain the cause of restraint to the patient

- Restraint belts and straps should be made of leather and be wide

- Physical restraints should not use as punishment

- The patient can see at least one technician

- Speak with the patient in a calm and slow tone during a restraint

- Take care of the patient's head during restraint

- Only restraint the patient's hand and legs.

- Check the patient's vital signs, especially the pulse of extremities under the restraints.

- Extremities should not be under pressure,

- The patient should be able to move extremities under the restraints.

- Do not use damaged equipment for restraining patients

- The ambulance stretcher used for restraint its height should be at the

lowest level

- Control patient for the level of consciousness and dehydration

- All actions should be documented

- Do not put the patient in a prone position

- Call the police

- After physical restraining, pharmacological restraint should be applied
It is essential to distinguish between the physical and psychological causes of these symptoms because it completely changes the course of treatment. In some reference books and articles, there are general protocols for managing psychotic patients [25]. But in most of the previously written protocols, the management of a symptom such as aggression or agitation has been considered [24-27]. Allen, et al. recommended different pharmacological and behavioral interventions inpatient with agitation in different situations [24, 28].

Gargia et al. suggested several recommendations on the assessment of agitation emphasize the importance of identifying any possible medical cause [29]. Most of the existing protocols are related to patient management in the hospital emergency department, and less attention has been paid to earlier stages, such as the pre-hospital stage.

In the current protocol, the first thing is the safety of technicians, their patients, and people who are in the scene. Almost all references related to acute psychotic symptoms consider the existence of a safe environment as the necessary precondition for patient management $[15,16]$. These include the safety of the environment and the management of patients' behaviors that may be harmful to themselves and others. Therefore, this protocol as well as predicting such behaviors and managing them according to international protocols is also considered.

Because of the legal aspects, police presence was also expected in the case of using mandatory treatments. This is also important for the safety of the technician, and it has been addressed in previous protocols [30]. Also, considering the priority of saving a patient's life, early assessment of his/her vital signs is a priority [31] which we put in the primary steps of treatment. Because of the importance of diagnosing physical disorders that have symptoms similar to mental disorders, we placed making a differential diagnosis after examining vital signs.

The second point in the present protocol is to consider the overlap of many symptoms of physical illness with psychiatric disorders and to consider the differential diagnosis. Therefore, vital signs and evidence of lifethreatening disorders should be examined. Impairment of the judgment and lack of co-operation in psychiatric patients can worsen the situation according to the cultural conditions in Iran.

In majority of patients' cases, living with families and intervention of families in the process of the treatment 
as well as utilizing the capacity of families in the evaluation of the patient can be very helpful, which is highly considered in the present protocol. Also, in addition to the common spiritual principles associated with each patient (such as empathy, complete acceptance and being non-judgmental, etc.) paying attention to the specific religious and spiritual cultures and areas of each region that affect the therapeutic relationship with the patients is of great importance [32].

In the current protocol, like previous ones, nonpharmacological management is preferred over pharmaceutical methods. Calming the patient without medication is the priority, and drug therapy is the next priority. At the time of drug administration, in compliance with the general principles of pharmacological therapy, the priority is with the minimum dose and the oral administration root. Injectable drugs are the next priority [29]. The goal of drug therapy is to calm agitated patients without decreasing their level of consciousness [33]. However, based on available drugs and their side effects, and the possibility of drug abuse, we chose different types of drugs for the protocol. Lorazepam can be a useful drug, given the short time in the pre-hospital emergency and the need to calm the patient down with the least side effect. Lorazepam can be used in mild to moderate emergencies and in patients who are more cooperative [34].

Injectable benzodiazepines and antipsychotics such as olanzapine (considering its interaction with lorazepam and the possibility of cardiovascular collapse), ziprasidone and haloperidol are the last lines of treatment $[19,35,36]$. The use of injectable midazolam as recommended in other protocols [37] was not approved by experts despite its rapid and practical effect on sedation, because of the risk of abuse. Other antipsychotics such as aripiprazole were not approved in previous protocols like our protocol and are not recommended [29]. The use of physical restraint is proposed for patients who have not responded to primary treatments and may harm themselves and others. In some protocols, special beds with certain height are recommended for physical restraint. Given that these beds do not exist in Iran, restraint with ordinary beds and wide and leather straps was recommended. Indications, safety recommendations, and limitations for using physical restraint in our protocol are consistent with other protocols. The use of physical restraint should be accompanied by chemical restraint (use of medication to calm the patient) [22, 23]. Special attention for patients with delirium is similar to previous protocols [23].

\section{Study limitations}

The study has several limitations. Firstly, a systematic review of the study has not been conducted and only a review of existing articles was undertaken. And secondly, Due to the limited availability of medicines in the emergency room of Iran, the suggested treatments may not necessarily be the best choices.

\section{Conclusion}

It seems that, given the lack of similar protocols in our country in the past, this protocol can be a solution to improve emergency technician training. Such summarized protocols can be used for rapid reviews immediately before being exposed to a patient with an acute psychiatric condition.

\section{Supplementary information}

Supplementary information accompanies this paper at https://doi.org/10. 1186/s12873-020-00313-2.

Additional file 1. Pre-hospital emergency protocol for mental disorders.

\section{Abbreviations}

EMS: Emergency medical service; PCP: Phencyclidine

\section{Acknowledgments}

This study was performed under the supervision of the Spiritual Health Research Center of Iran, University of Medical Sciences.

\section{Authors' contributions}

FS and SSM designed the study, conducted the review and performed the data analysis. FH, MB, and HNS assisted in the study design and data analysis. ZM, MKA, and SVS interpreted the data and drafted the manuscript. All authors read and approved the final manuscript before submission.

\section{Funding}

This research received no specific grant from any funding agency in the public, commercial, or not-for-profit sectors and in the design of the study and collection, analysis, and interpretation of data and in writing the manuscript there is no role for any funding body.

\section{Availability of data and materials \\ Not applicable.}

\section{Ethics approval and consent to participate}

The study was approved by the Ethics Committee of the Iran University Medical Sciences under number IR.IUMS.REC.1397.1255. All participants (expert panel and emergency technicians and emergency technical assistants) were informed about the study and only those providing written informed consent were enrolled in the study.

\section{Consent for publication}

Not applicable.

\section{Competing interests}

The authors declare that they have no competing interests.

\footnotetext{
Author details

${ }^{1}$ Spiritual Health Research Center, Iran University of Medical Sciences, Tehran, Iran. ${ }^{2}$ Mental Health Research Center, Department of Psychiatry, School of Medicine, Iran University of Medical Sciences, Tehran, Iran. ${ }^{3}$ School of Behavioral Sciences and Mental Health (Tehran Institute of Psychiatry), Iran University of Medical Sciences, Tehran, Iran. ${ }^{4}$ Preventive Medicine and Public Health Research Center, Iran University of Medical Sciences, Tehran, Iran. ${ }^{5}$ Deputy of Technical and Operations of the Emergency Organization, Tehran, Iran. ${ }^{6}$ Emergency Organization, Tehran, Iran. ${ }^{7}$ Mental Health Research Center, School of Behavioral Sciences and Mental Health (Tehran Institute of Psychiatry), Tehran, Iran.
} 
Received: 27 October 2019 Accepted: 26 February 2020

Published online: 16 March 2020

\section{References}

1. Vandad Sharifi M, Hajebi A, Radgoodarzi R. Twelve-month prevalence and correlates of psychiatric disorders in Iran: the Iranian mental health survey, 2011. Arch Iran Med. 2015;18(2):76.

2. Naghavi M, Abolhassani F, Pourmalek F, Lakeh MM, Jafari N, Vaseghi S, et al. The burden of disease and injury in Iran 2003. Popul Health Metrics. 2009;7(1):9.

3. Emond K, O'Meara P, Bish M. Paramedic management of mental health related presentations: a scoping review. J Ment Health. 2019;28(1):89-96.

4. Roberts L, Henderson J. Paramedic perceptions of their role, education, training and working relationships when attending cases of mental illness. Australasian J Paramed. 2009;7(3):Article 990317.

5. Cuddeback G, Patterson PD, Moore CG, Brice JH. Utilization of emergency medical transports and hospital admissions among persons with behavioral health conditions. Psychiatr Serv. 2010;61(4):412-5.

6. Rees N, Rapport F, Snooks H. Perceptions of paramedics and emergency staff about the care they provide to people who self-harm: constructivist metasynthesis of the qualitative literature. J Psychosom Res. 2015;78(6):529-35.

7. Shaban R. Paramedics' clinical judgment and mental health assessments in emergency contexts: Research, practice, and tools of the trade. Australasian J Paramed. 2015;4(2):Article 990177

8. Parsons V, O'Brien L. Paramedic clinical decision-making in mental health care: a new theoretical approach. J Paramed Pract. 2011;3(10):572-9.

9. Spencer C, Archer F. Paramedic education and training on cultural diversity: conventions underpinning practice. Australasian J Paramed. 2015;4(3):Article 990203.

10. Macpherson R, Dix R, Morgan S. A growing evidence base for management guidelines: revisiting ... guidelines for the management of acutely disturbed psychiatric patients. Adv Psychiatr Treat. 2005;11(6):404-15.

11. Hadi F, Khosravi T, Shariat SV, Nadoushan AHJ. Predictors of physical restraint in a psychiatric emergency setting. Med J Islam Repub Iran. 2015;29:296

12. Cunha S, Soares-Oliveira M, Pereira N. Early psychological intervention in prehospital emergency care systems. J Emerg Med. 2009;36(4):404-6.

13. Levine SD, Colwell CB, Pons PT, Gravitz C, Haukoos JS, McVaney KE. How well do paramedics predict admission to the hospital? A prospective study. J Emerg Med. 2006;31(1):1-5.

14. The Cochrane collaboration. Cochrane intervention review: external peer referee checklist for protocols. Version 2; 2013.

15. Sadock V. Synopsis of psychiatry behavioral sciences/clinical psychiatry. Translate by Rafiei H, Sobhaniyan KH Tehran: Arjmand. 2007;2:135-82.

16. Sadock BJ, Sadock VA, Ruiz P. Comprehensive textbook of psychiatry 10th edition. United States of America: Wolters Kluwer; 2017

17. Arthur Z, Berg AZ, Bell CC, Tupin J. Clinician safety: assessing and managing the violent patient. New Dir Ment Health Serv. 2006;2000(86):9-29.

18. Zun L, Wilson MP, Nordstrom K. Treatment goal for agitation: sedation or calming. Ann Emerg Med. 2017;70(5):751-2.

19. Wilson MP, Pepper D, Currier GW, Holloman GH Jr, Feifel D. The psychopharmacology of agitation: consensus statement of the American Association for Emergency Psychiatry Project BETA psychopharmacology workgroup. Western J Emerg Med. 2012;13(1):26.

20. Battaglia J. Pharmacological management of acute agitation. Drugs. 2005; 65(9):1207-22.

21. McKinney C, Renk K. Atypical antipsychotic medications in the management of disruptive behaviors in children: safety guidelines and recommendations. Clin Psychol Rev. 2011;31(3):465-71.

22. Currier GW, Allen MH. Emergency psychiatry: physical and chemical restraint in the psychiatric emergency service. Psychiatr Serv. 2000;51(6):717-9.

23. Simpson SA, Joesch JM, West II, Pasic J. Risk for physical restraint or seclusion in the psychiatric emergency service (PES). Gen Hosp Psychiatry. 2014;36(1):113-8.

24. Allen M, Currier G, Carpenter D, Ross R, Docherty J. The expert consensus guideline series. Treatment of behavioral emergencies 2005. J Psychiatr Pract. 2005;11:5-108 quiz 10-2.

25. Stone CK, Humphries RL. Current essentials of emergency medicine: Lange Medical Books/McGraw-Hill; 2005
26. Dib JE, Adams CE, Kazour F, Tahan F, Haddad G, Haddad C, et al. Managing acutely aggressive or agitated people in a psychiatric setting: a survey in Lebanon. Med J Islam Repub Iran. 2018;32:60.

27. Zeller SL, Citrome L. Managing agitation associated with schizophrenia and bipolar disorder in the emergency setting. Western J Emerg Med. 2016; 17(2): 165

28. Allen MH, Currier GW, Hughes DH, Reyes-Harde M, Docherty JP. Treatment of behavioral emergencies. Postgrad Med. 2001;109.

29. Garriga M, Pacchiarotti I, Kasper S, Zeller SL, Allen MH, Vazquez G, et al. Assessment and management of agitation in psychiatry: expert consensus. World J Biol Psychiatry. 2016;17(2):86-128.

30. Pacciardi B, Mauri M, Cargioli C, Belli S, Cutugno B, Di Paolo L, et al. Issues in the management of acute agitation: how much current guidelines consider safety? Front Psychiatry. 2013;4:26.

31. ALLEN MH, CURRIER GW, HUGHES DH, DOCHERTY JP, CARPENTER D, ROSS R. Treatment of behavioral emergencies: a summary of the expert consensus quidelines. J Psychiatr Pract ${ }^{\oplus}$. 2003;9(1):16-38.

32. Sweat MT. How do we prepare for emergency spiritual care? J Christ Nurs. 2016:33(2):120.

33. Correll CU, Yu X, Xiang Y, Kane JM, Masand P. Biological treatment of acute agitation or aggression with schizophrenia or bipolar disorder in the inpatient setting. Ann Clin Psychiatry. 2017:29(2):92-107.

34. Kendrick JG, Goldman RD, Carr RR. Pharmacologic Management of Agitation and Aggression in a pediatric emergency department-a retrospective cohort study. J Pediatr Pharmacol Ther. 2018;23(6):455-9.

35. Powney MJ, Adams CE, Jones H. Haloperidol for psychosis-induced aggression or agitation (rapid tranquillisation). Cochrane Database Syst Rev. 2012;11.

36. Huf G, Alexander J, Gandhi P, Allen MH. Haloperidol plus promethazine for psychosis-induced aggression. Cochrane Database Syst Rev. 2016;11.

37. Chan EW, Taylor DM, Knott JC, Phillips GA, Castle DJ, Kong DC. Intravenous droperidol or olanzapine as an adjunct to midazolam for the acutely agitated patient: a multicenter, randomized, double-blind, placebocontrolled clinical trial. Ann Emerg Med. 2013;61(1):72-81.

\section{Publisher's Note}

Springer Nature remains neutral with regard to jurisdictional claims in published maps and institutional affiliations.

Ready to submit your research? Choose BMC and benefit from

- fast, convenient online submission

- thorough peer review by experienced researchers in your field

- rapid publication on acceptance

- support for research data, including large and complex data types

- gold Open Access which fosters wider collaboration and increased citations

- maximum visibility for your research: over $100 \mathrm{M}$ website views per year

At $\mathrm{BMC}$, research is always in progress.

Learn more biomedcentral.com/submission 